38

$18 / 19$

LA-7728-MS

Informal Report

\section{Verification Station for Sandia/Rockwell \\ Plutonium Protection System}

DR. 2677

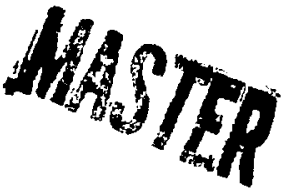

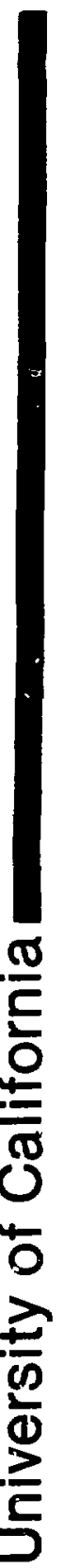


VERIFICATION STATION

FOR

SANDIA/ROCKWELL PLUTONIUM PROTECTION SYSTEM

\author{
by
}

\author{
N. Nicholson, R. D. Hastings, C. N. Henry, and D. R. Millegan
}

\begin{abstract}
A verification station has been designed to confirm the presence of plutonium within a container module. These container modules [about $13 \mathrm{~cm}$ (5 in.) in diameter and $23 \mathrm{~cm}(9$ in.) high] hold sealed food-pack cans containing either plutonium oxide or metal and were designed by Sandia Laboratories to provide security and continuous surveillance and safety. After the plutonium is placed in the container module, it is closed with a solder seal. The verification station discussed here is used to confirm the presence of plutonium in the container module before it is placed in a carousel-type storage array inside the flutonium storage vault. This measurement represents the only technique that uses nuclear detectors in the plutonium protection system.
\end{abstract}

\section{INTRODUCTION}

The Los Alamos Scientific Laboratory (LASL) and Sandia Laboratories, Albuquerque (SLA) have been developing various techniques directed at improving the security and degree of surveillance for special nuclear material (SNM), particularly plutonium.

The LASI, approach has been to develop inexpensive shelf rietectors that continuously monitor the gamma radiation and weight of the material, together with a verification station that measures the gamma and neutron radiation and the weight of a plutonium-bearing container. A verification signature is recorded that can be used to ascertain that the contents of the measured container have remained unchanged during storage. The verification station acts as a backup for the shelf system, provides security in depth, and serves to separate the material and personnel traffic entering the vault. A verification signature is obtained when material is placed in the verification chamber while the personnel traffic is scanned by a gamma-sensitive doorway monitor for unauthorized SNM or radioactive material.

The Sandia Plutonium Protection System (PPS) is designed to greatly enhance the physicai security of the material by concentrating on the three major areas of material control and protection, personnel control, and material accountability. These major aspects of the PPS provide an excellent security system by denying unauthorized access to the plutonium and by providing continuous monitoring of the material. The 280-can demonstration of the PPS designed for the large plutonium storage vault at Hanford contains 8 carousels, each capable of storing 35 container modules (CMs). The carousel is designed so that only one container is accessible at 


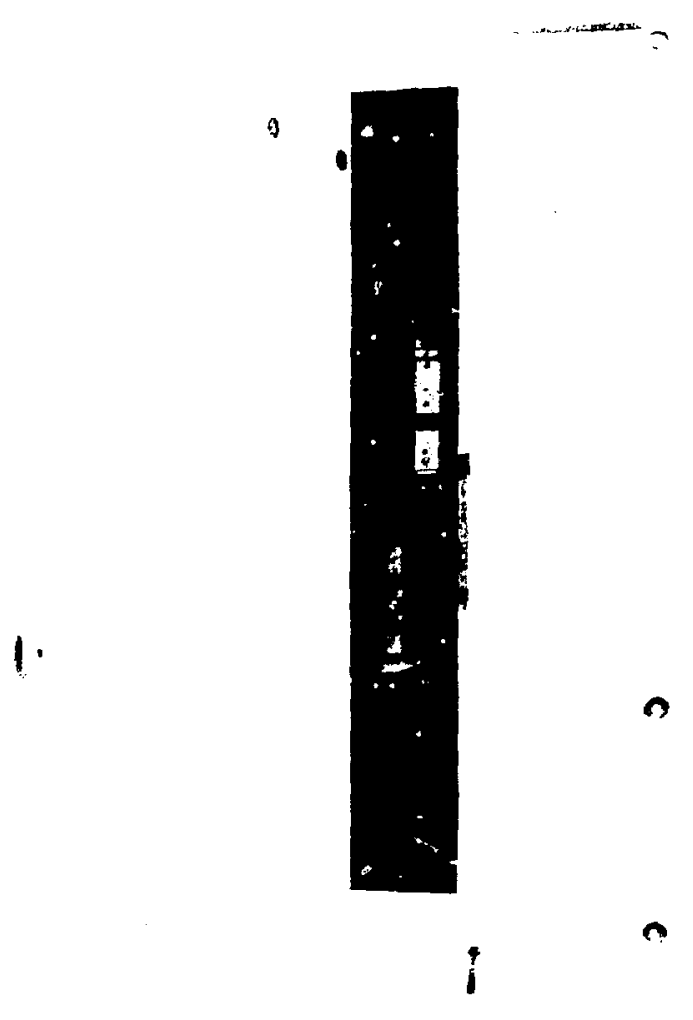

Fig. 1.

$S L A$ carousel with access door open.

any time. Figure 1 shows a carousel with its chamber door open. In the orientation shown, the CMs that are visible from the door cannot be removed unless the carousel is rotated so that one position lines up with the doorway opening. The $\mathrm{CM}$ is equipped with electronics and sensors that provide a monitoring computer with the serial number of the container, an authentication code, the temperature of the electronics and food-pack can, and a sensor that detects any deformation of the food-pack can. The external features of the CM are shown in Fig. 2. The hermetic connector at the top of the module is the link between the CM electronics and the SLA cornputer. Once the $\mathrm{CM}$ is placed in the carousel, a bolt in the carousel drops into the security tang and prevents the CM from being removed until the tang bolt is withdrawn by computer control. The physical layout of the CM electronics is shown in Fig. 3. This cutaway shows the location of the food-pack can within the CM as well as the location of the ther-

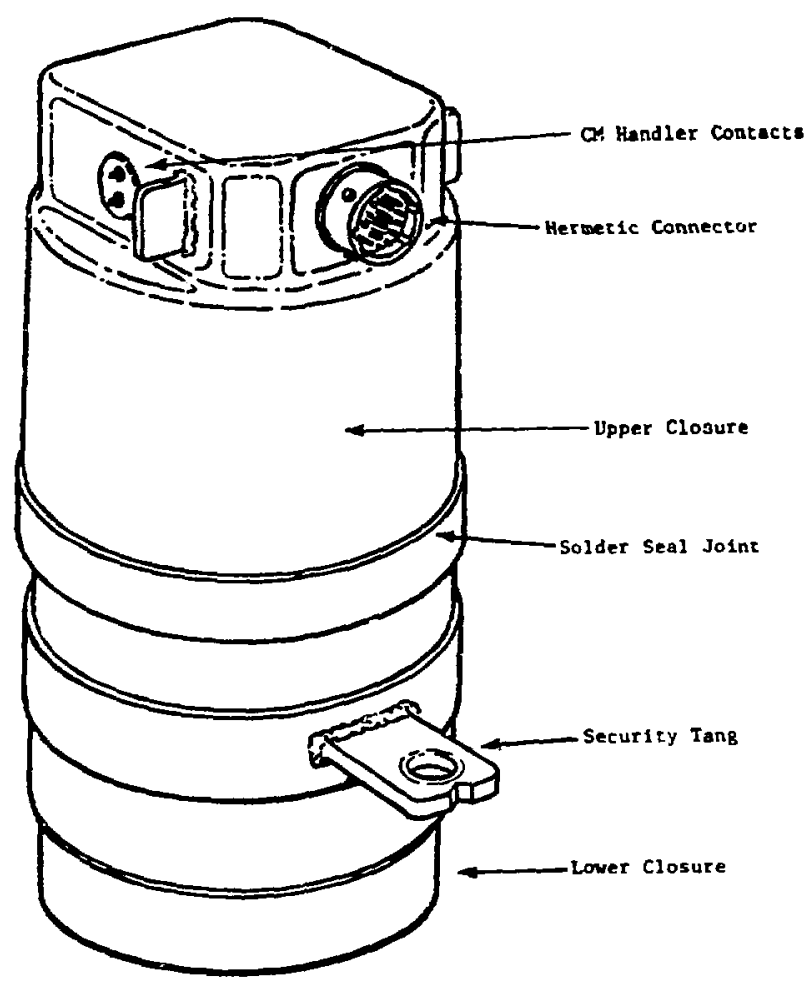

Fig. 2.

Container module (CM).

mistor that monitors the temperature and a linear potentiometer that senses any bulging of the foodpack can during storage.

The PPS provides an advanced level of security to the material under its surveillance, but it does not have a means of assuring the actual presence of plutonium within the sealed containers as they enter the PPS. A proposal was made to incorporate an instrument into the PPS that was capable of confirming the presence of plutonium within the sealed container module. The proposed LASL verification station would furnish assurance that an omission uf substitution, deliberate or accidental, has not occurred in shipping, handling, or packaging of the plutonium in the interval between the last process assay and entry into the PPS. This proposal has resulted in the development of an instrument that is simple to use and that furnishes confirmation within a 4-s counting time that plutonium is contained within the CM. A description and discussion of this verification station and ways of improving it are contained in this report. 


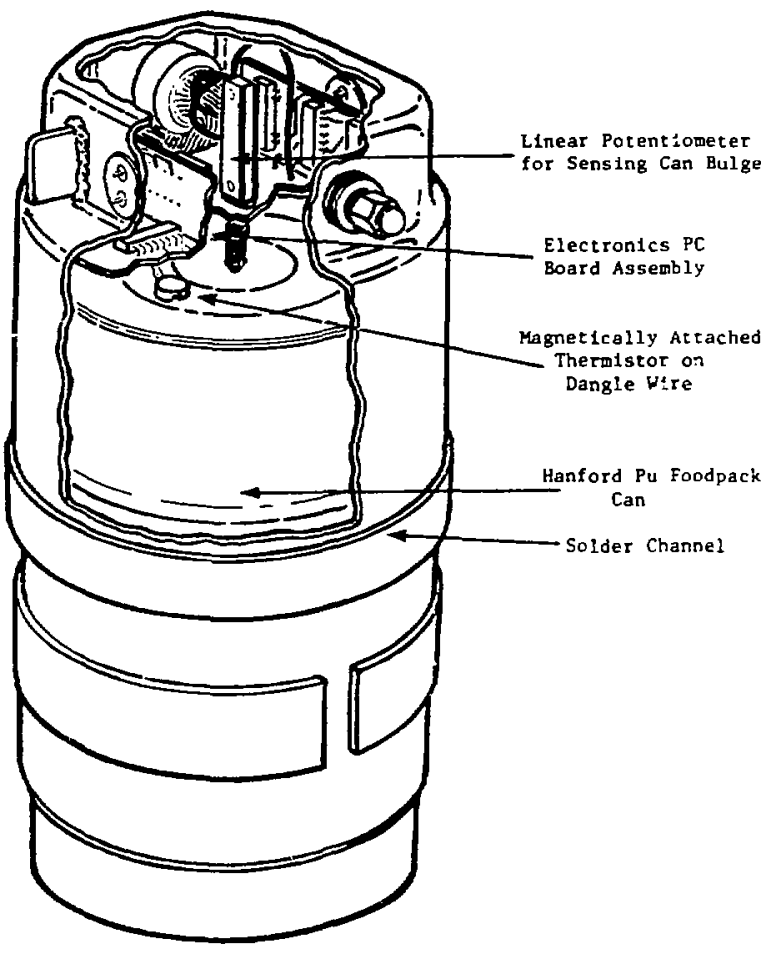

Fig. 3.

Electronic features of $C M$.

Before the development of a verification station began, the Department of Energy (DOE), Office of Safeguards and Security, requested that a study be made to determine whether a general type of verification station could be developed that would be useful in many facilities, rather than one specifically designed for the PPS. A survey was made that revealed that a universal verification station would be extrernely difficult to develop because of the many parameters that must be accommodated. A copy of the letter survey, sent to 13 facilities, and a response to Safeguards and Security summarizing the results of the survey are shown in the Appendix. The basic verification station discussed in this report closely approaches a universal verification station concept since its mear.urements are not strongly dependent on the sumerous parameters discussed in the Appendix. However, the price paid for simplicity and universality is lack of quantitative information. An advanced verification station that will address this particular failing will be discussed later.

\section{DEVELOPMENT OF THE BASIC VERIFICA- TION STATION}

Designing a verification station specifically for the PPS is made somewhat easier because the CMs are of a uniform size and shape, so the attenuation of the gammas emitted is the same in all cases. In addition, only two types of plutonium will be stored in this system, plutonium metal $(2.0-2.2 \mathrm{~kg}, 4.5-17 \%$ $\left.{ }^{20} \mathrm{Pu}\right)$ and plutonium oxide $(750-900 \mathrm{~g}, 6.0-6.7 \%$ ${ }^{240} \mathrm{Pu}$ ). However, even with these advantages it is difficult to obtain an accurate assay of the material in a rapid straightforward manner.

The requirements imposed on a verification station by $\varepsilon$. system such as the PPS include rapid operaticn and verification, uncomplicated procedure, high reliability, and a low false alarm rate. The necessity for a fast measurement becomes important when the PPS is applied to a large vault, such as the Rockwell plutonium storage vault at Hanford (the location of the PPS 280-can demonstration). A verification measurement that requires more than a fraction of a minute will tend to imperle the traffic flow and movement of material. Also, any verification procedure that must be followed should be easy to understand and perform.

The development of the verification station was divided intu t:vo pheses. A basic station to fulfill all the requirements discussed above and to provide a confirmation rather than a verification (qualitative rather than quantitative) was designed so that it could be used in the PPS during its development and demonstration phases. An advanced verification station would subsequently be designed to improve the quality and accuracy of the measurements, but would not necessarily satisfy the requirements $e_{\perp}^{r}$ an operational vault.

The basic verification station has been designed to detect both gamma and neutron radiation and to measure the gross weight of the CM. The gamma detector is an $8-\mathrm{mm}$ by 50 - $\mathrm{mm}$ Geiger-Muller (GM) tube that operates at $425 \mathrm{~V}$ and is shielded by $6 \mathrm{~mm}$ of lead. A rectangular slot, approximately the size of the tube, allows the gamma radiation to enter the detector, which is located directly beneath a $\mathrm{CM}$ during the measurement. Two $\mathrm{BF}_{\mathrm{s}}$ detectors, $5 \mathrm{~cm}$ by $66 \mathrm{~cm}$, moderated by $5 \mathrm{~cm}$ of polyethylene, are placed along both sides of the container in a horizontal position. Because the $\mathrm{CMs}$ are $13 \mathrm{~cm}$ in diameter, 


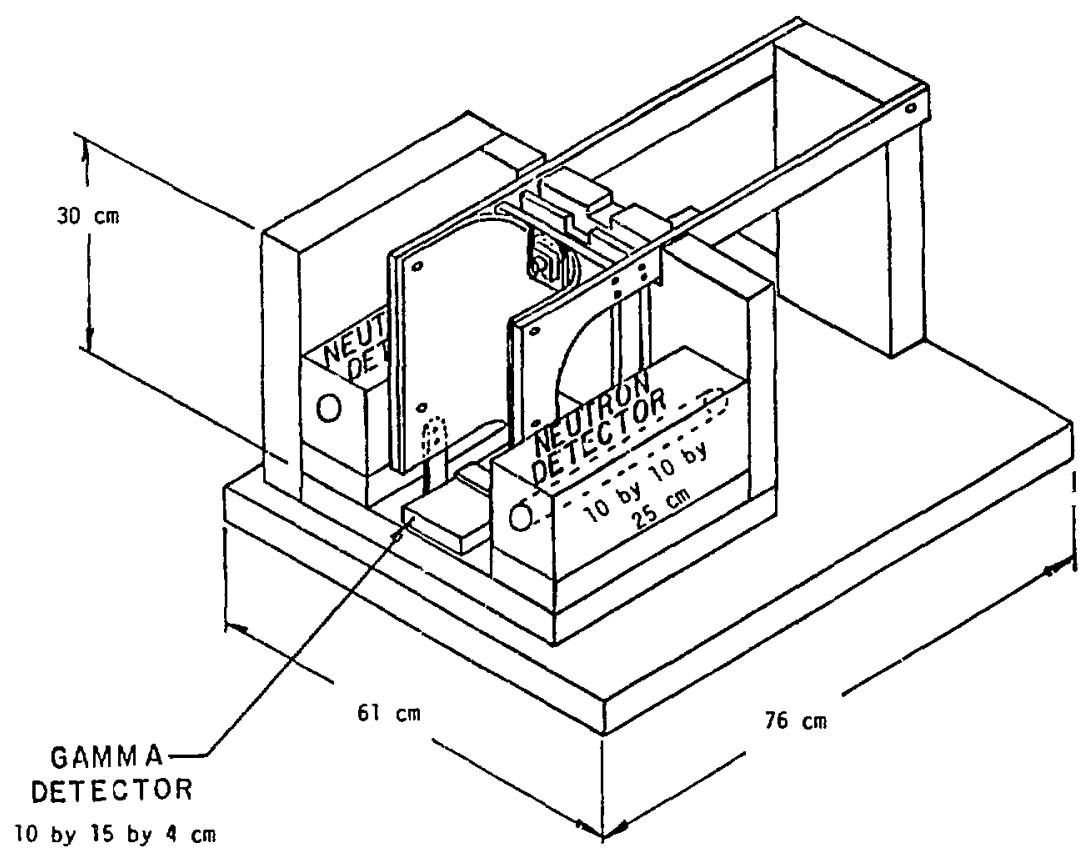

Fig. 4.

Internal details of the plutonium verification chamber.

only $25 \mathrm{~cm}$ of each tube is moderated edjacent to the container. A sketch of this arrangement is shown in Fig. 4. The SLA housing includes a spring scale to measure the weight of the $C M$, and a connector that the $C M$ is plugged into during verification. The connector relays the information contained within the $C M$, as well as the weight information, to the SIA computer. Figure 5 shows the verification chamber with the chamber door open showing the connector and support base that is part of the spring scale. The preamplifier used with the neutron detectors and the electronics required for the GM tube are both inside the chamber. All other electronics are housed in an adjacent equipment rack, shown in Fig. 6, which includes two high-voltage power supplies, two scalers, a timer-scaler, two linear amplifiers and discriminators, and the logic module that analyzes the incoming signals from the gamma and neutron detectors.

The plutonium verification logic module has twc counting registers, one neutron and one gamma, each with a capacity of 16 bits. A background count can be taken and stored in each. In addition, a threshold setting is set into each counter using a 16- bit dip-switch. This threshold is the delta count that must be exceeded before the presence of gamma or neutron radiation is verified. Figure 7 shows the front panel of the logic module. At least one indicator light is on at all times so that the status of the module is always apparent. An explanation of the logic system can be given most easily by describing the functions of the buttons and lights sequentially from top to bottom.

\section{Background Count}

To initialize the logic module, a background count is taken, during which the red LED labelled countin-progress is lit. A background cannot be taken when a CM is connected to the verification chamber because the background thus obtained would be erroneously high. If the background start button is pushed with a $\mathrm{CM}$ in the chamber, the invalid. condition LED at the bottom oi the module will light and an audible alarm is activated to warn the operator of the error. 


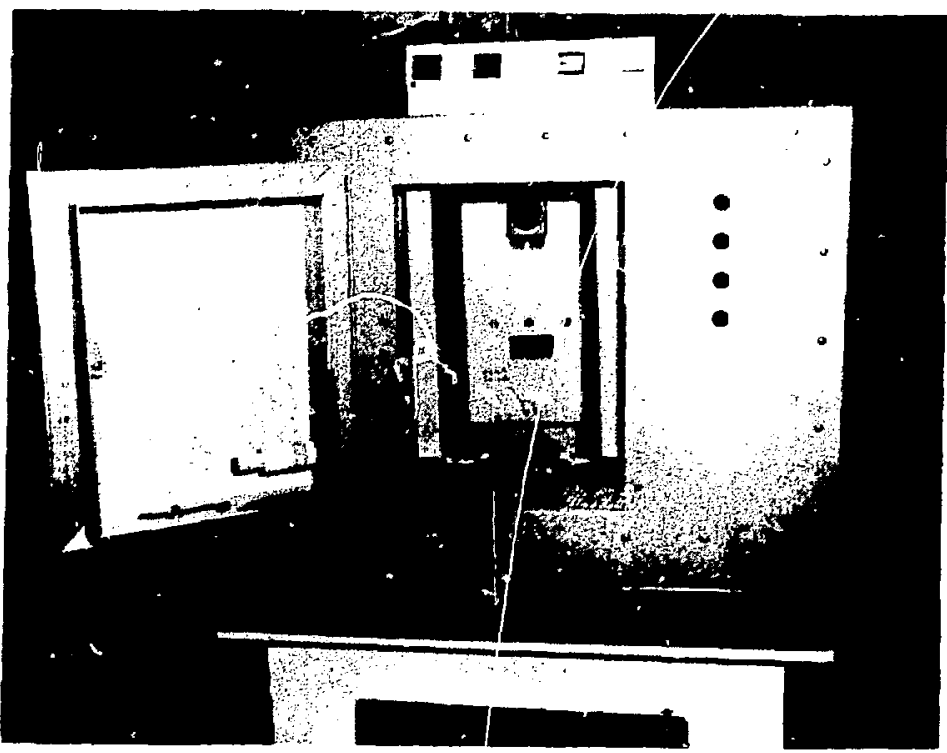

Fig. 5.

External view of the plutonium verification chamber with the chamber door open.

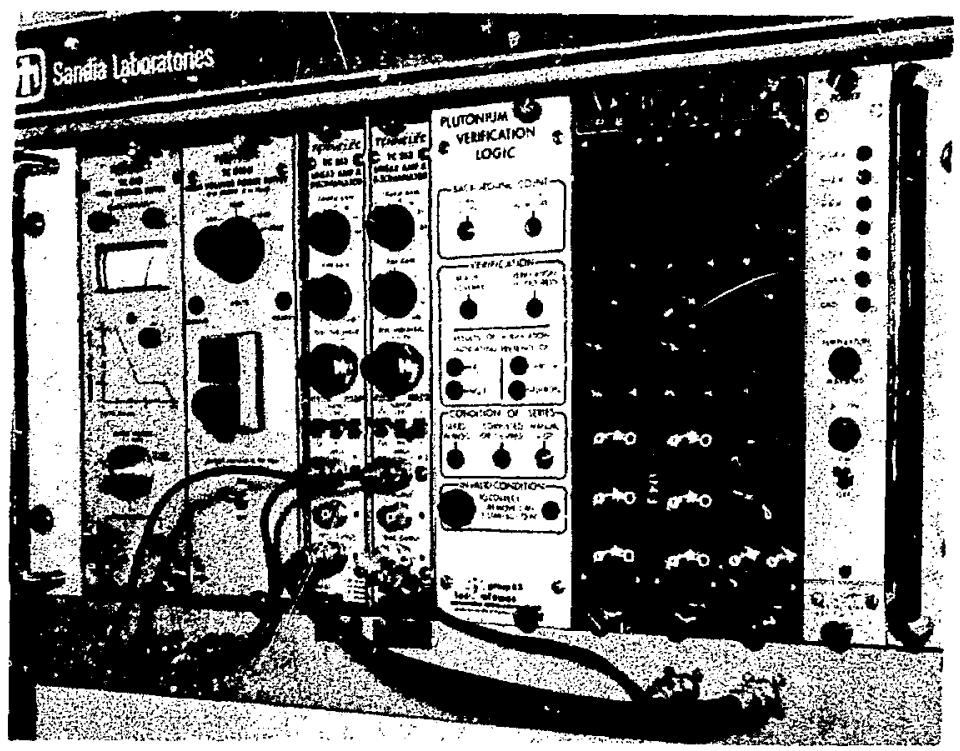

Fig. 6.

Verification station electronics. 


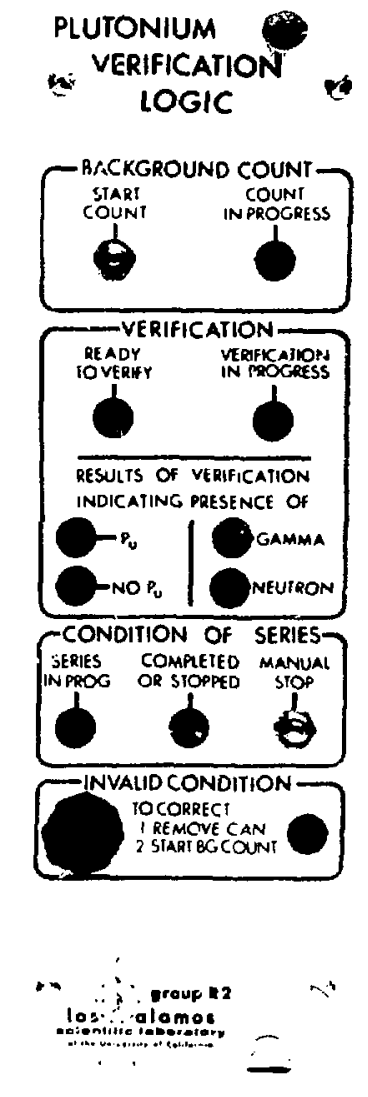

Fig. 7.

Plutonium verification station logic module.

\section{Verification}

When the background count has been completed, the ready-to-verify light comes on. This signals the operator that he can insert the CM into the chamber and close the door. The door closure initiates the counting period for verification. For the amounts of plutonium expected in the PPS, a counting interva] of $4 \mathrm{~s}$ is adequate. During the counting period, the verification-in-progress indicator is glowing.

\section{Results of Verification}

After the 4-s verification period, several combinations of light may be on. If both the gamma and neutron thresholds are exceeded, both the gamma and neutron lights come on, as does the plutoniumpresent light. Any other combination of gamma and neutron lights will result in a no-plutonium indication, such as gamma only, neutron only, or neither light. Both the gamma and neutron indicators will come on as soon as the threshold is exceeded in their respective registers. However, the plutoniumpresent and no-plutonium indicators are not activated until the verification counting period is complete.

\section{Condition of Series}

The condition of the verification lights at the completion of the verification measurement will remain until the $\mathrm{CM}$ is removed from the verification chamber. When the CM is removed, these lights are extinguished and the series-in-progress indicator comes on. An internal timer allows $3 \mathrm{~min}$ to elapse between completion of a verification and series termination. At that time, the completed-or-stopped and the series-in-progress LED lights go off. The 3min timer allows enough time for all five (maximum) CMs contained in a single secure transport module (STM) to be verifed and to time out before a new STM arrives. (An STM provides security to the plutonium while it is being moved between secure areas and resembles a minivault on wheels because it contains a carousel with storage for five CMs. The carousel arrangement of the STM is shown in Fig. 8. The STM shroud has been replaced in Fig. 9 and is shown adjacent to a dock specifically designed to accept the STM. This dock is located at the CM packaging room.) When a series has been terminated, either by timing ont or by depressing the manual stop switch, a new series is initiated by taking a new background count. If a CM is allowed to remain in the verification chamber longer than 3 min and a new background count is attempted, the invalid-condition indication is given and an audible 


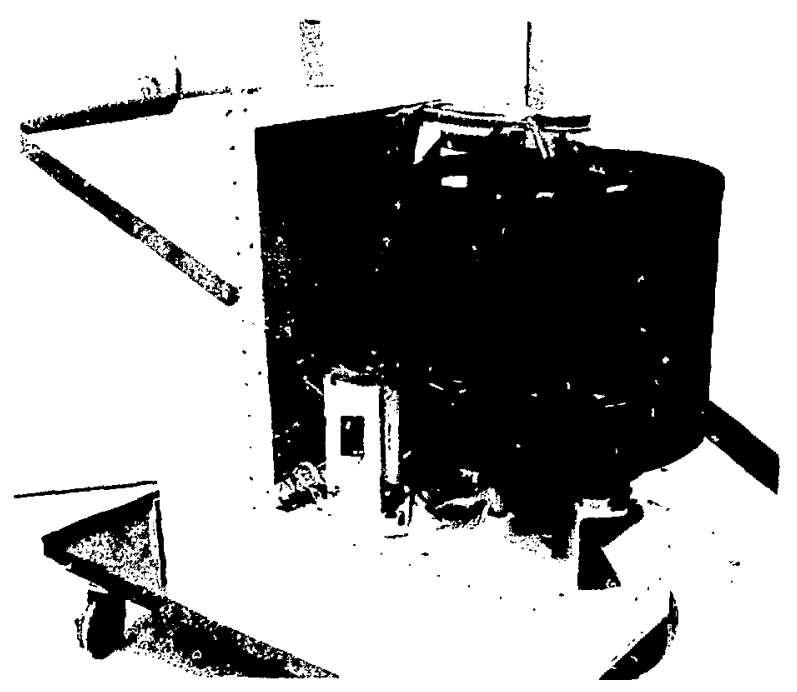

Fig. 8.

SLA STM with shroud removed.

alarm is sounded by the module to alert the operator that a CM is still in the station.

The back panel of the logic module is pictured in Fig. 10 and shows signal inputs for the gamma and neutron detectors, 8 manual switch that simulates a can-connect closure and the interface connector that supplies the SLA computer with the status of the various indicators discussed earlier. The SLA computer supplies the LASL logic module with a closure signal that indicates when the CM is connected to the verification station and the chamber door is closed.

The interface to the Sandia computer is accomplished by supplying eight closures through the back panel connector, which represent the following conditions.

1. Series in progress.

2. End of series.

3. Invalid condition.

4. Background in progress.

5. Ready for verification.

6. Verification in progress.

7. Plutonium present.

8. Plutonium not present.

The LASL logic module requires only one relay closure from the SLA system and is closed when the $\mathrm{CM}$ is placed in the chamber, connected to the special ' $M$ fitting, and the chamber door is closed.

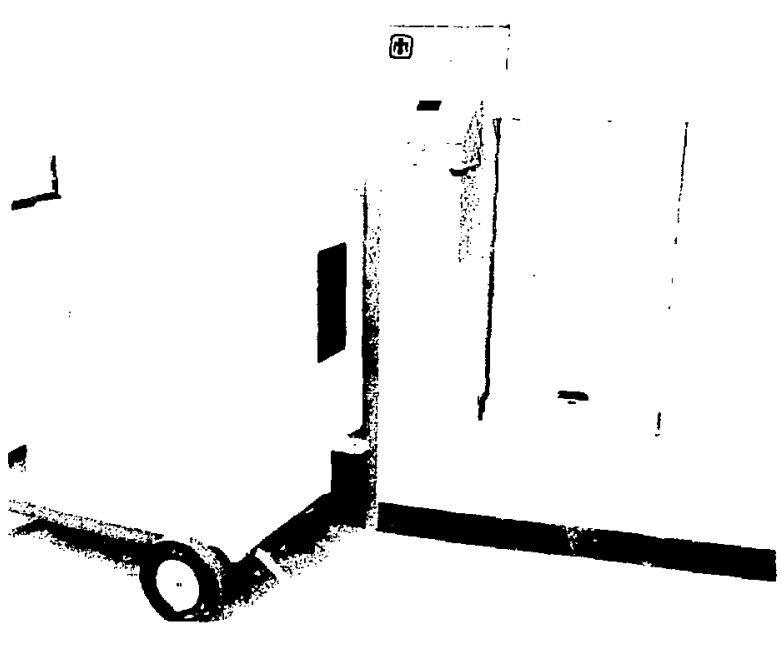

Fig. 9.

SLA STM adjacent to an STM portal.

This closure inutiates the verification. The resultsof-verification indicators displayed upon completion of the verification are cleared when the chamber door is opened and the CM removed, at which time the ready-to-verify LED is activated.

The threshold settings for the gamma and neutron registers can be made by removing the side panel of the module and setting in the desired threshold using a series of dip-switches. Figure 11 shows the logic board with the four 8 -bit dip-switches. The registers for each detector are arranged vertically, with the left column for the neutron register and the right column for the gamma register. Note that a wire at the top of the board connecis sockets 1 and 16 of an empty IC base. This connection appears in the circuit diagram shown in Fig. 12, near the top and just left of center. This jumper can be connected between socket 1 and sockets $12-16$ and is used to vary the time required for verification of $a$ container, which is also the same time used to cbtain a background count. The 3-min time delay that automatically ends a series is also a variable, but a jumper is not provided for this. The registers used in both the gamma and neutron counters are up-down counters. When a background is taken, registers 13-21, -22, $-23,-24$ (neutron registers) and $13-33,-34,-35,-36$ (gamma registers), shown in Fig. 12, count up and store a background. When a verification is in 

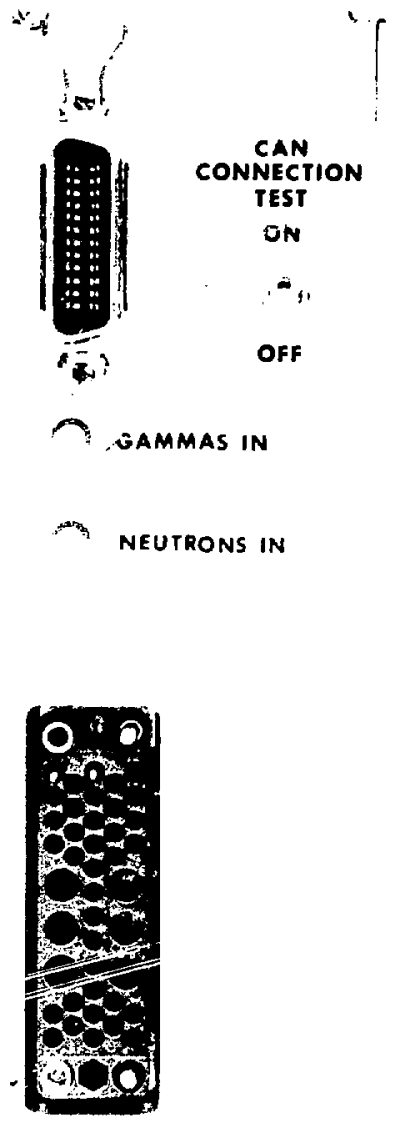

Fig. 10.

Rear view of the plutonilim verification station. logic module.

progress, the counters count down from the stored background until a zero condition is met. The dipswitches and registers that set the thresholds are to the right of the background registers and these counters start to count down from the thresholds set by the dip-switches when the zero condition is satisfied by the background counters. As soon as the threshold counters reach a zero condition, the neutron or gamma-present indications are given by activating the respective LED. The plutoniumpresent or no-plutonium decisions are made at the completion of the verification counting interval.

Under normal conditions, the signal measured from the CM will be many times the background levels at the location of the verification station. When this is the case, small background variations

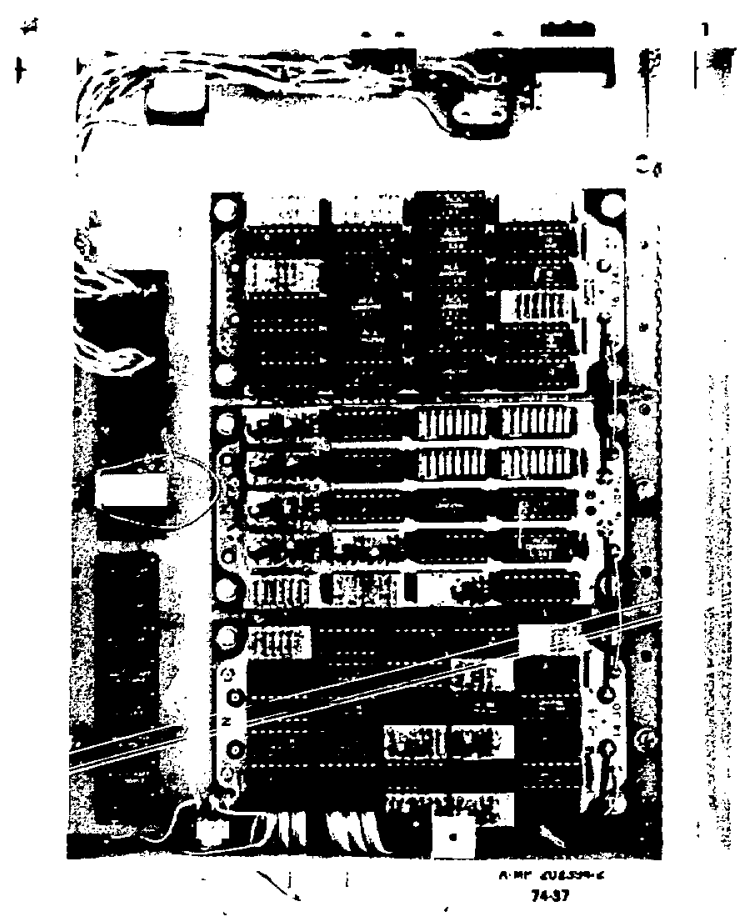

Fig. 11.

Plutonium verification station logic module electronics board.

will not affect the sensitivity of the chamber. However, if background levels are encountered that are as large or larger than the signal levels, then the delta-type logic that is being used in this system has the interesting feature of maintaining a nearly constant source sensitivity for variations in the background as large as a factor of 10 . This behavior of the delta logic is discussed by Kunz et al. in an internal LASL report entitled "Hand-Held Special Nuclear Material Monitor For Personnel And Vehicle Searches."

\section{UTILITY OF THE BASIC VERIFICATION STATION}

The basic verification station was designed specifically for the SLA PPS. Because the verifications are not quantitative they are not strongly dependent upon such variables as container and material, geometry, density of the plutonium, 


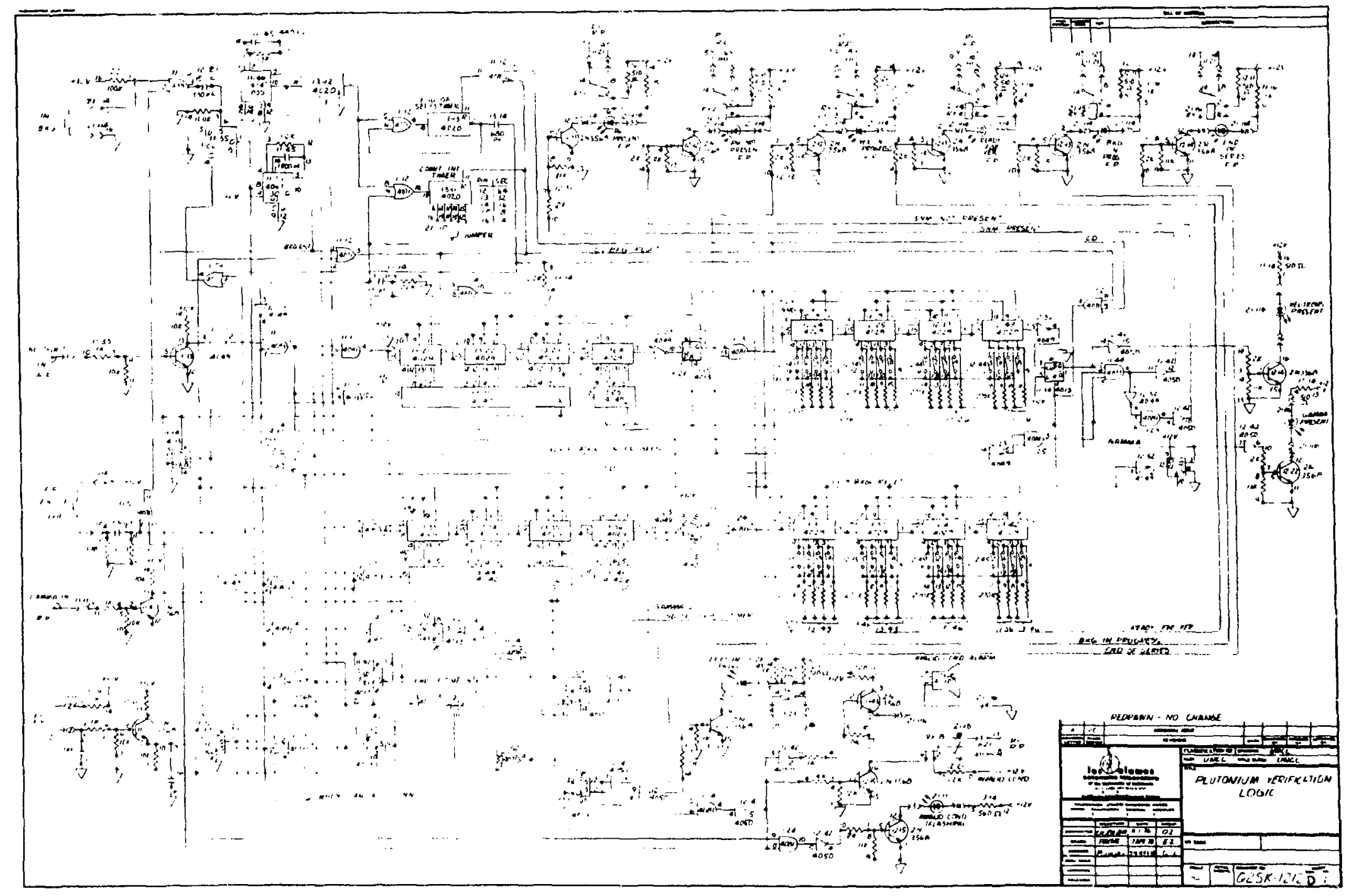

Fig. 12.

Circuit diagram of the plutonium verification station logic module. 
isotopic ratio, chemical composition, background levels, and other parameters that will affect a precision assay. Because of the insensitivity to these parameters, this type of station could be used to confirm the presence of plutonium for a wide range of material types and could fulfill the requirements of a universal verification station. Although the lack of quantitative information greatly reduces the effectiveness of these measurements in detecting the absence of diverted material, the speed with which a simple confirmatory determination can be made may not only be attractive, but necessary. As discussed earlier, the basic station requires $4 \mathrm{~s}$ to perform neutron and gamma measurements and an estimate of the weight. It is anticipated that a more quantitative measurement, such as foreseen for the advanced station, could take $10 \mathrm{~min}$ or more, which might cause a serious bottleneck at the entrance to a storage vault. A solution to this difficulty would be to use both a basic and an advanced verification station in some combination. For example, some fraction of the traffic might be randomly measured in the advanced station, the eny offering some probability of discovering a divertor whose strategy is to take many small samples of material.

If the thresholds of the basic verification station are set at $a$ fraction above normal background, any material that emits both gammas and neutrons will satisfy both threshold settings and give a plutoniumpresent indication. The material stored in the SLA PPS during the demonstration period at Hanford was divided into two categories, metal and oxide. The oxide samples have a $20 \%$ spread in mass and a $10 \%$ spread in the ${ }^{200} \mathrm{Pu}$ content. The metal samples only vary $10 \%$ in weight but almost $400 \%$ in ${ }^{240} \mathrm{Pu}$ content. Since this material is representative of the inventory of SNM normally stcred in the Rockwell vaults; the threshold settings can be set for the weakest neutron and gamma emitter in the vault inventory. When the station is operated with these higher threshold settings, the basic verification station provides a semiquantitative verification and a more effective obstacle to would-be divertors.

The station also provides the gross weight of the $\mathrm{CM}$, and, by knowing the tare weight of both the $\mathrm{CM}$ and the inner food-pack cans, a reasonahle estimate can be made of the net weight of the plutonium contained within that CM. Furthermore, since the plutonium metal samples average close to $2.2 \mathrm{~kg}$ and the plutonium oxide samples average about $0.85 \mathrm{~kg}$, the weight reading can be used to determine whether the material is oxide or metal.

An improvement in the basic system would be to have specific threshold settings for the metal and oxide samples. When the weight measurement indicates whether the sample is metal or oxide, the computer could notify the logic module with another set of closures that would select the appropriate threshold settings. This additional feature would not significantly alter the verification time or complexity, but would enhance the utility of the basic station.

\section{CONCEPT OF AN ADVANCED VERIFICA- TION STATION}

An advanced verification station will provide a quantitative measurement for the plutonium within the CM, which will compare the neasured value with the nominal value declared for that CM. In addition, if a CM fails to meet the verification criteria, ihen a numerical result can determine the degree of frilure. This information is useful in deciding what further action will be necessary for an item that has failed a verification check. This type of system requires that the station be supported by a mini- or microcomputer that is interfaced at some level with the main system compiter.

An assay measurement that can independently determine the weight and isotopic ratios of the plutonium is preferred for an advanced station. The techniques under investigation include neutron time correlation analyses coupled with a neutron coincidence counting technique. This combination should produce a result which gives the number of grams of ${ }^{210} \mathrm{Pu}$ in the sample. An accurate weight measurement coupled with the tare weight of the $\mathrm{CM}$ and food-pack can will yield the net weight of plutonium. An estimate can be made for the weight of ${ }^{239} \mathrm{Pu}$ if the weight of ${ }^{210,241,242} \mathrm{Pu}$ can be neglected or estimated.

A gamma-ray detector, such as a $\mathrm{NaI}(\mathrm{Tl})$, is being considered to supply additional confidence to the measurement $\dot{z}$. If a 100-channel gamma-ray spectrum is taken of the material, the prominent gamma-ray peaks can be identified and can allow the identification of the principal gamma-ray emitters within the CM. High-resolution gamma-ray spectroscopy is also a possibility for this application 
but requires longer counting times, considerably more software development, and a larger number of channels. To utilize fully the information obtained from a germanium gamma-ray detector, a major effort will be necessary to develop the software, develop a library of gamma-ray energies, obtain a larger core memory, and develop a sophisticated gain stabilization system that can be integrated into the computer and CAMAC system. Isotopic information can be obtained from high-resolution gamma-ray spectroscopy, but this will also require an extensive software development program and additional time for verification.

There are some disadvantages to an advanced verification station in a working vault. The time required for a reduced variance, coincidence neutron, and gamma-ray spectrum determination is about 10 min-an unacceptably long time if the traffic through. the vault is greater than 30-40 containers per day. In addition, a sophisticated technique, such as that being considered for the advanced station, will give a number of possible responses for a verification measurement. This probably will require additional training for the material handlers, station operators, and security personnel.

Some of the disadvantages that an advaricer. station presents can be overcome simply by using buth a basic and an advanced station in some complementary arrangement. If the basic verification station would normally measure all the normal throughput into the storage vault, a random sampling of this traffic could be measured by the advanced station and could act as a double check on the operation of the basic station and provide a deterrent to would-be divertors. In addition, any containers that fail to sarisfy the thresholds set by the basic station could be automatically checked by the advanced station before any alarm is given. The random selection of the containers to be measured by the advanced station could be made by the computer and would assure that no operator bias is introduced into the selection process.

\section{ACKNOWLEDGMENTS}

The authors thank H. D. Arlowe, Sandia Laboratories, Albuquerque, for providing photographs of the SLA-built equipment shown in this report, and also the many individuals who provided the information requested in the survey of storage facilities that appears in the Appendix. 


\section{UNIVERSITY OF CALIFORNIA \\ LOS ALAMOS SCIENTIFIC LABORATORY \\ (Contract W-7405-2na-36) \\ P. O. Box 1663 \\ Low Alamoe, New Merico 8754}

IN REPLY

Rerex тo: $R-2-76-415$

September 2, 1976

Phone: (505) 667-451.2

kr. Horace L. Henry

Battelle Northwest Laboratory

P. O. Box 999

Richland, WA 99352

Dear Mr. Henry:

The Los Alamos Scientific Laboratory (Group R-2) has been asked by the Division of Safeguards and Security to conduct a survey of selected facilities involved in some degree with the storage and safeguarding of plutonilm. As a result of increasing worldwide terrorism, and increasing publicity as to the possible vilnerability of stored plutonium, techniques which provide for continuous surveillance and/or tight security of this material are being investigated by the LASL and Sandia laboratories. Many factors determine the usefulness and practicality of such schemes including, for example, oost, existing facility modifications, plant specific considerations, desired or required or possible level of accuracy, reliability and security, just to list a very few.

Because of the large nurber of plants and plant specific variables involved, IASL is attempting to determine the pertinent factors and which of these are most common. This knowledge would perhaps allow a storage safeguards system to be designed that would be adaptable to a greater number of facilities. In order to arrive at these factors, we are requesting that you elaborate on the points iisted at the end of this note.

In order to make the following questions more meaningful, I am including a sketch of one of several possible vault safeguard systems being currently considered. Figure 1 shows two portals into an SNM storage vault. One portal is used only for containers of SNM, the other is for personiel. The SNM portal performs a verification ${ }^{1}$ or assay whenever material enters or leaves the vault. This verification station may be cortuosed of a combination of neutron and gamma detectors, an accurate scale, an autamatic label reader, etc. The personnel doorway is monitored by a gamma sensitive doorway monitor and by a metal detector. ${ }^{2}$ The vault itself is monitored by a number of sensors that will keep each container, or group of containers, under continuous surveillance. This quickly summarizes one possible scheme for a storage/safeguards system. If you have other ideas that you would like to consider for your vault, please include these in your response. 
With this model of safeguaraing an SNM storage vault, the following parameters needed to be defined for your specific vault or facility. Please include existing vaults and those under construction in your reply.

1. Number of containers per day (average and extreme).

2. Average residence time of container in vault (and exicremes).

3. Geametry of containers (range of sizes, shapes, etc.).

4. Geometry of SNM (button, castings, powder, etc.).

5. Mass of SNM (range of masses of SNM and total weight if non-metal).

6. Range of isotopic compositions in single vault.

7. Chenical form of SNM (metal, oxide, etc.).

8. Type of multiple packaging employed (plastic sags within cans, cans within cans, etc.).

9. Type of item identification (handwritten label, bar code label, etc.).

10. Radiation levels, gamma and neutron, at selected points within and outside.

11. Heat generation in vault and ambient temperature.

12. Shelf configuration on which the containers are stored.

13. Nondestrurtive assay equipment now on hand at your lacility.

The following is a list of mnsiderations that are of interest and that you might like to cament on:

1. Mode of operation that seems feasib]e (automatic/mechanical vs manual for inventory control., nuclea- safety, ease of handling, health physics, or safeguards.

2. Data processing requirements (item identification, transfer of data to computer, data storage, etc.).

3. Accuracy requirements.

4. Reliability reguirements (tolerance to false alarms, power outages, etc.).

5. Active vs passive verification/assay techniques.

6. Current physical inventory practice.

It is anticipated that further information will be required following this initial contact. This might take the form of another more specific list of questions or a personal visit to your facility. I am looking forward to hearing from you with your reply to this query and with any corments or suggestions that you care to make.

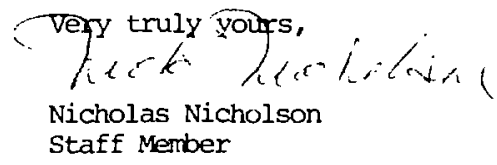

N':ec

Attachment: Figure 1

\footnotetext{
Verification can be defined here as a crude assay.

2 This implies that personnel will not be allowed to have metal in any form on their person upon entering and leaving the vault.
} 


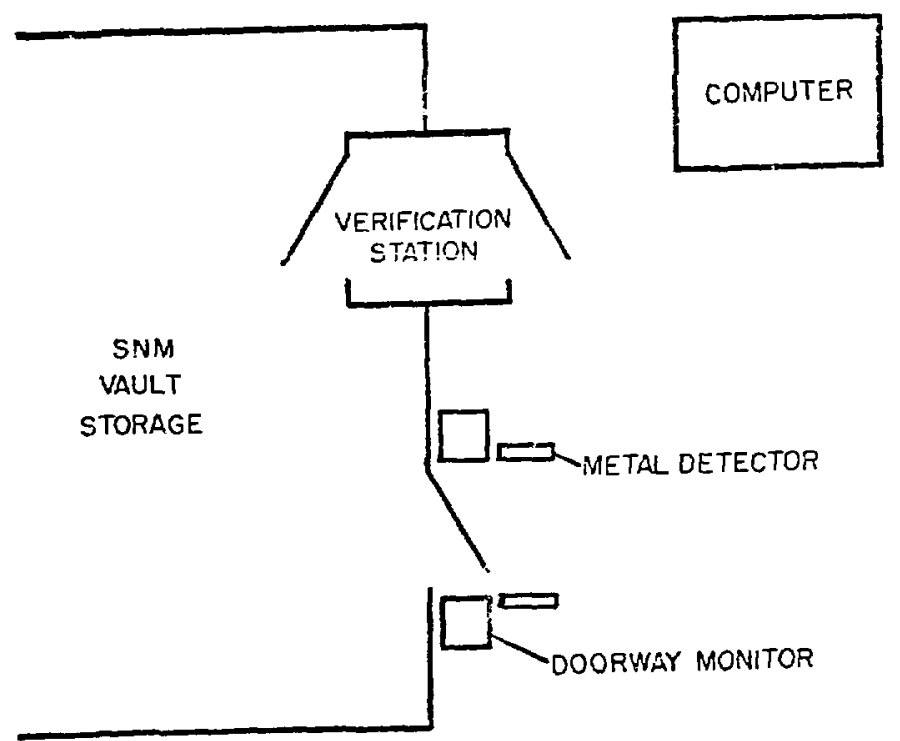

FIG.I, VAU:T LAYOUT 
$\mathrm{R}-2-76-415$

Distribution

Ronald B. Perry

Argonne National Laboratory

9700 South Cass Avenu =

Argonne, II 60439

Vincent F. FitzPatrick

Hanford Enrineering

Develr $x_{i}$ int Laboratory

P. O. Bux 1970

Richland, WA 99352

Wilbur D. McNeese

CMB-I1 MS-328

Dean Braden

Atlantic Richfield Hanford Company

F. O. Box 250

Richland, WA 99352

Richard A. Neff

Monsanto Research Corporation

P. O. Box 32

Miamisburg, OH 45342

J. H. Gillette

Oak Ridge National Laboratory

P. O. BOX X

Oak Ridge, TN 37830

Edward D. Marshall

Oak Ridge Operations Office

U. S. Energy Research and Development

Adninistration

P. O. BOX E

Oak Ridge, TN 37830

N. E. Hall

General Electric Company

vallecitos Nuclear center

P. O. Drawer B

Pleasonton, CA 94566
September 2, 1976

Arthur B. Shuck

Argonne National Laboratory

9?00 South Cass Avenue

Argonne, IL 60439

William Demerschman

Hanford Engineering

Development Laboratory

P. O. Box 1970

Richland, WA 99352

Kenneth Freiberg

Rockwell International

Atomic International Division

Rocky Flats plant

P. O. Box 464

Golden, $C 080401$

Joe W. Jordan

Atlantic Richfield Hanford Campany

P. O. Box 250

Richland, WA 99352

William J. Maeck

Allied Chemical Corporation

Idaho Chemical Programs - Operations office

550 2nd Street

Idaho Falls, ID 83401

I. B. Shappert

Dak Ridge National Laboratory

P. 0 . Box $X$

Dak Ridge, TN 37830

Richard Duda

Westinghouse Electric Corporation

Nuclear Fuel Division

P. O. Box 355

Pittsburg, PA 15230

Edward Kurtz

General Electric Company

Vallecitos Nuclear Center

P. O. Drawer B

Pleasonton, CA 94566 
$R-2-76-415$

Distribution

Carl Crouthamel

EXXON Nuclear Company

2101 ibrn Rapids Road

Richland, WA 99352

Horace L. I'enry

Battelle Northwest Laboratory

P. O. Box 999

Richland, WA 99352

Information copy:

David F. Bailey

Division of Safeguards and security

U. S. Energy Research and

Development Administration

Washington, DC 20545
$-2-$

September 2, $1970^{\circ}$

William Heer

Nuclear Materials Division

(NMD) of B\&W

609 N. Warren Avenue

Apollo, PA 15613

Har iid E. Ransom

Di: ector, Safeguards

Ricilarú operationis úficice

P. O. Box 550

Richland, Washington 99352

Cecil S. Sonnier

Sandia Laboratory

Division 1751

P. O. Box 5800

Albuquerque, NM 87115 


\section{UNIVERSITY OF CALIFORNIA \\ LOS ALAMOS SCIENTIFIC LABOKATORY \\ (Contruct W-7405-eno-36) \\ P. O. Box 1663 \\ Los Alamos, New Mexico B7544}

IN REPLY

REPER TO: Q-2, MS-562

April 18, 1977

Dr. Sam C. T. McDowell

USERDA

Division of Safeguards and Security

Washington, DC 20545

Dear Dr. McDowe11:

As you know, LASL has conducted a survey of selected

facilities involved to some degree with the storage and safeguarding of special nuclear material (Ref. R-2-76-415). Techniques are being considered by LASL Q-2 that provide for continuous surveillance of this material while in storage and for additional security at the portal to these storage vaults. There are a large number of factors involved in these considerations that bear directly upon the design, usefulness, and pricticality of such schemes.

The purpose of the questionaire was to define these pertinent factors and to determine which of these are most common. It was hoped that this information might perhaps allow a storage safeguards system to evolve that would be adaptable to a greater number of facilities.

Thirteen facilities were sent a request for information concerning their respective storage facility. Ten responses were received over a seven-month period. These responscs, together with personal visits to several facilities, provided the following conclusions.

AN EQUAL OPPORTINITY EMPLOYER 
April 18, 1977

page 2

\section{Survey Results}

A. Traffic in and out of most vaults is quite low, especially if the vaults are used exclusively for storage.

B. Residence time of material in storage vaults (as opposed to temporary storago vaults used for $R \delta D$ and transient material) is generally long (months).

c. Geometry of containers varies considerably and includes small cylindrical cans, tuna fish cans, fruit cans, ice cream cans, $5,15,30$, and 55 gallon barrels, bird cages, fuel rods, fuel rod bundles, and a multitude of other sizes and shapes. Each storage facility has a wide range of container sizes and shapes, although some vaults do use containers that are within a narrow size range.

Container sizes and types of packaging used throughout the varjous storage facilities have nn epparcnt staniaids. There are, of course, similarities between some of the containers, but many more examples exist of large divergences between types of ! ackaging used for similar materials.

D. The geometry of the SNM vartes from powders, oxtde pellets, and microspheres to rods, plates, disks, she11s, and buttons.

E. The mass of SMM per container ranges from grams to many kilograms. Some vaults at the larger facilities bave containers with kilogram quantities of SNM only. In general, however, most vaults have a wide range of stored masses.

F. The isotopic ratios encountered generally are the full range possible: depleted to fully enriched uranium; plutonium containing from $2.5 \%$ to $42 \% 240 \mathrm{Pu}$.

G. Generally the chemical composition is metal or oxide Pu or U. Occasionally alloys, carbides, nitrates, and an assortment of scrap, :ialts, and incinerator ash occur.

H. Multiple containers have two or three layers of packaging using various combinations of metal cans and plastic bags. 
April 18, 197\%

page 3

I. Labelling of cans is almost exclusively by haniwritten labels or an ID number stamped on the container. No aitonatic label readers or bar code labels were encountered.

J. Radiation levels within most vaults are moderate and are low outside the vault. However, the low neutron readings outside most vaults are still tens to hundreds of times normal background, and are therefore high when precision neutron measurements are considered in the vicinity.

K. Except for facilities handling large quantities of $2{ }^{38} \mathrm{Pu}$, the ambient temperature of storage vaults is unaffected by the material stored there.

L. Two general types of shelf configurations were encountered. The standard horizontal shelves stacked vertically are most common. At several facilities, the diumond array is used and the cans are stored lying on their sicies instead of upright. Some shelf arrays have indivicual compartments with doors.

M. Of the facilities considered, most have some sort of NDA equipment available.

\section{Paxameters}

A. Of the factors that were considered in the survey, the following are not judged to be limiting factors in the design of a verification/assay station:

1. Number of containers per day in most cases are not large enough to warrant special design considerations.

2. Average residence time of containers in vaults generally varies from several weeks to several years.

3. Almost exclusively, item identification is accomplished by handiritten labels. Some method of inputting this information directly into a computer is needed to reduce transcription errors and save time. Special design considerations may be required for this, but they should be minor factors. 
April 18, 1977

page 4

4. Heat generation in the vault due to the SNM is negligible in most cases.

B. Factors that are judged to be significant in the design of verffication/assay station are the following:

1. Container geometry and type of multiple packaging.

2. Material geometry and mass.

3. Whether Pu or $\mathrm{U}$ or both.

4. Range of isotopic mix.

5. Chemical form.

6. Radiation 1evels, neutron and gamma, at station.

7. Accuracy réquirements.

8. Reliability requirements (number of false alarms tolerated).

\section{Verification/Assay Stations}

In cases where the above variables are reasonably constant, the design of verification stations is greatly simplified and the achievable accuracy is greatly enhanced. For example, the Sandia/ARCHO demonstration program will store material in welldefined contuiners and well-defined material type and cherical form (metal or oxide $\mathrm{Pu}$ ). Although this situation is good from a design standpoint, there are still many difficulties in designing a station that can provide assay quality measurements.

If the accuracy requirements are moderate to high then the design of a verification/assay station becomes very dependent upon the parameters noted in II.B. If, on the other hand, the verification criteria are low, less exact measurements can be made. There are sone situations where a1l that is needed is an indication of whether 
April 18, 1977

page 5

or not material is present. For example, if both gammas and neutrons are simply detected froti a package, this measurement carr be defined as verifying the presence of Pu. Such a measurement, however, cannot distirguish between a Pu source and a composite source containing an arbitrary neutron and gamma source. The advantage to such a simple system is that the design parameters for the verification/assay station are relaxed considerably and the station can therefore accommodate a wide spectrum of material types and geometries at low cost. In most cases, however, the accuracy and reliability requirements will be high and will require more sophisticated techniques and technology.

IV. Shelf Systems

Mothods of monitoring materiai wirile iu storage will be even more plant-specific and are not presently used. Most plants currently rely on item identification coupled with some sort of tamper indicator (such as seals) for most inventory requirements. Any means of automating vault inventory will require tailoring the proposed system to fit the existing vault or modifying the existing vault to fit the system or a combination of the two. A materials handling system such as a stacker-retriever will generally require a totally new vault facility.

v. Summary

Even though there are common factors shared by many of these storage facilities, there is at present far too much variability in the important factors that determine the design of a vault portal security and continuous inventory system. In order to be able to perform an accurate verification/assay, the factors 1 isted in II.B. must be well defined before a nuclear assay technique is chosen. This is evidenced by the large number of nuclear assay techniques that have been developed to date, each designed to solve a particular problem that has a set of well-defined characteristics. 
Apri1 18, 1977

page 6

This leads to the conclusion that the design of a vault security system that includes a verification/assay station and/or a shelf monttoring system, will be very dependent upon plant-specific vartables and will generally be tallored for each facility and even for each storage vault at that factlity. As we proceed with the development program at LASL (TA-21 and TA-55) and with the Sandia/ARHCO demonstration program, guidelines and performance criteria for such systems will also be developki.

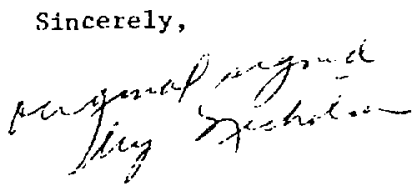

Nicholas Nicholson

NN: mef

xc: Keepin/Chambers, Q-DO/SG, MS-550

N. Nicholson, Q-2

Q-2 files

Mail \& Records (2), MS-150

Hans $E$. Hansen, Sandia, Albuquerque, $M$

B. J. Ellerthorpe, USERDA, Richland operations office, Richland, Washington 